Article

\title{
Experimental Investigation of Surfactant Partitioning in Pre-CMC and Post-CMC Regimes for Enhanced Oil Recovery Application
}

\author{
Ahmed Fatih Belhaj ${ }^{1, * \mathbb{D}}$, Khaled Abdalla Elraies ${ }^{1}$, Mohamad Sahban Alnarabiji ${ }^{2}$, \\ Juhairi Aris B M Shuhli ${ }^{1}$, Syed Mohammad Mahmood ${ }^{1}\left(\mathbb{D}\right.$ and Lim Wan Ern ${ }^{1}$ \\ 1 Department of Petroleum Engineering, Universiti Teknologi PETRONAS, Seri Iskandar 32610, Perak, \\ Malaysia; khaled.elraies@utp.edu.my (K.A.E.); juhairi.shuhli@utp.edu.my (J.A.B.M.S.); \\ mohammad.mahmood@utp.edu.my (S.M.M.); estherlwe@gmail.com (L.W.E.) \\ 2 Department of Chemical Engineering, Universiti Teknologi PETRONAS, Seri Iskandar 32610, Perak, \\ Malaysia; mohamad.alnarabiji@gmail.com \\ * Correspondence: belhaj91@gmail.com; Tel.: +601121545848
}

Received: 2 May 2019; Accepted: 31 May 2019; Published: 17 June 2019

\begin{abstract}
The applications of surfactants in Enhanced Oil Recovery (EOR) have received more attention in the past decade due to their ability to enhance microscopic sweep efficiency by reducing oil-water interfacial tension in order to mobilize trapped oil. Surfactants can partition in both water and oil systems depending on their solubility in both phases. The partitioning coefficient $\left(\mathrm{K}_{\mathrm{p}}\right)$ is a key parameter when it comes to describing the ratio between the concentration of the surfactant in the oil phase and the water phase at equilibrium. In this paper, surfactant partitioning of the nonionic surfactant Alkylpolyglucoside (APG) was investigated in pre-critical micelle concentration (CMC) and post-cmc regimes at $80^{\circ} \mathrm{C}$ to $106^{\circ} \mathrm{C}$. The $\mathrm{K}_{\mathrm{p}}$ was then obtained by measuring the surfactant concentration after equilibration with oil in pre-cmc and post-cmc regimes, which was done using surface tension measurements and high-performance liquid chromatography (HPLC), respectively. Surface tension (ST) and interfacial tension (IFT) behaviors were investigated by performing pendant and spinning drop tests, respectively—both tests were conducted at high temperatures. From this study, it was found that APG was able to lower IFT as well as ST between water/oil and air/oil, and its effect was found to be more profound at high temperature. The partitioning test results for APG in pre-cmc and post-cmc regimes were found to be dependent on the surfactant concentration and temperature. The partitioning coefficient is directly proportional to IFT, where at high partitioning intensity, IFT was found to be very low and vice versa at low partitioning intensity. The effect of temperature on the partitioning in pre-cmc and post-cmc regimes had the same impact, where at a high temperature, additional partitioned surfactant molecules arise at the water-oil interface as the association of molecules becomes easier.
\end{abstract}

Keywords: surfactant; surface tension; interfacial tension; partitioning; high temperature; EOR

\section{Introduction}

During the past 60 years, significant development has been made on oil recovery methods [1-5]. Chemical flooding was found to be among the most efficient Enhanced Oil Recovery (EOR) methods [6,7]. Surfactants are special classes of molecules which have a hydrophobic tail and hydrophilic head group, and the most stable condition for these molecules is at the oil-water interface [8-10]. Surfactants have a great potential in EOR applications and are used to enhance the recovery process efficiently by increasing the quantity of the residual oil extracted after the secondary recovery process, which can account for approximately $60 \%$ of the original oil in place [11-13]. The surfactant flooding process 
is implemented by injecting surfactants into the reservoir along with other chemicals. During the surfactant flooding process, favorable phase behavior is targeted to achieve ultra-low interfacial tension (IFT) between oil and water in order to mobilize the trapped oil [14]. The lowering of IFT between oil and water is obtained when surfactants are adsorbed on this liquid-liquid interface $[15,16]$. There are different factors that influence oil displacement efficiencies, such as salinity, temperature, mobility control, and surfactant formulations. The interactions of these factors emphasize the significance of understanding the surface and interfacial behavior in a fluid-fluid mixture system under reservoir conditions. The critical micelle concentration (CMC) is also an important aspect to study because at a concentration above this value the adsorption of surfactant at the interface becomes insignificant, indicating that the optimum reduction of surface or interfacial tension has been achieved $[17,18]$.

In general, surfactants can be transferred from the water phase into the oil phase through the interface in a diffusion-controlled process owed to the solubility of the surfactant in both phases. In surfactant-based water/oil systems, the ratio between the surfactant concentration in the oil phase and in the water phase under equilibrium conditions is known as the partitioning coefficient $K_{p}$. The partitioning of surfactants between the two phases has crucial effects on the surfactant flooding process; as well as determining the partitioning coefficient required to offer a better understanding of the partitioning mechanism $[8,19,20]$.

In oil and gas fields, surfactants are injected into the underground formations due to their ability in improving oil recovery and modifying the surface energy of reservoir rocks [21]. Many oil reservoirs have been reported to have a relatively high temperature $\left(70-130^{\circ} \mathrm{C}\right)$, where most of the surfactant flooding research has been rarely conducted in such high-temperature environments. These harsh conditions affect the thermal stability of surfactants and pose a challenge for surfactants to sustain ultralow IFT. Hence, understanding the variations of adsorption and partitioning taking place due to temperature increases is another obstacle [22-24]. The surfactant partitioning coefficient $K_{p}$ is highly affected by temperature. At low-temperature conditions, the surfactant rate of solubility is lower and the oil viscosity is relatively high, showing low surfactant mobility and thus a low partitioning rate $[25,26]$. Meanwhile, at high-temperature conditions, the free energy of the transfer of the surfactant molecules increases in the aqueous phase that transports the surfactant to the oil-water interface. The rate of surfactant solubility has a stronger impact on partitioning as it significantly accelerates at high-temperature conditions. Furthermore, oil viscosity decreases as temperature increases demonstrating additional unoccupied sites at the oil-water interface attracting more partitioned surfactant molecules $[25,27,28]$.

Different methods to determine the surfactant concentration in water and oil at equilibrium conditions were applied depending on the investigated regime. Numerous studies discussed the partitioning in the pre-cmc regime $[8,19,20,27,29]$, as well as in the post-cmc regime $[20,30-33]$. In the pre-cmc regime, a proposed method determining the portioning coefficient of surfactants was developed. The method uses surface tension measurements of surfactant solutions prior to mixing with crude oil, in order to generate an equilibrium surface tension isotherm [19]. Using the obtained isotherm, the unknown surfactant concentration is found after equilibration with oil. However, in the post-cmc regime, this method is not applicable since the surface tension of a surfactant solution will attain a constant trend above the cmc. Therefore, an analytical technique should be applied to determine the partitioning coefficients in the post-cmc regime, such as high-performance liquid chromatography (HPLC) [20].

In the available literature, only a few studies were conducted with limited success in evaluating the surfactant partitioning in environments of high temperature (above $100{ }^{\circ} \mathrm{C}$ ). The surface tension activity is tested first to determine the CMC. The main objective of this work is to demonstrate the significance of surfactant partitioning between oil and water in pre-cmc and post-cmc regimes given high-temperature conditions, with regard to the interfacial activity between the two liquid phases. A better understanding of the process is proposed using the connection between the partitioning and the interfacial tension to support the findings. 


\section{Materials and Methods}

\subsection{Materials}

The Alkylpolyglucoside (APG) (51.5\% active content) surfactant was supplied by BASF company (Ludwigshafen, Germany). A Malaysian crude oil sample was used in this work and its properties are listed in Table 1. The crude oil was supplied by PETRONAS Research Sdn. Bhd (Selangor, Malaysia).

Table 1. Properties of the crude oil.

\begin{tabular}{ccc}
\hline Temperature $\left({ }^{\circ} \mathbf{C}\right)$ & Density $\left(\mathrm{g} / \mathrm{cm}^{\mathbf{3}}\right)$ & API \\
\hline 25 & 0.8048 & 44.64 \\
80 & 0.75825 & 49.0 \\
106 & 0.7412 & 50.62 \\
\hline
\end{tabular}

All surfactant solution samples were prepared in brine with 32,743 ppm salinity (density $1.00736 \mathrm{~g} / \mathrm{cm}^{3}$ at ambient conditions) which matches the injected water salinity. The composition of the brine is given in Table 2. All samples were proven to be soluble and stable for 90 days at $80{ }^{\circ} \mathrm{C}$ and $106^{\circ} \mathrm{C}$. All chemicals were used as received without further purification, and all solutions were freshly prepared before the measurements.

Table 2. Brine composition.

\begin{tabular}{cc}
\hline Ion & Concentration $(\mathbf{p p m})$ \\
\hline Sodium $(\mathrm{Na})$ & 10080 \\
Calcium $(\mathrm{Ca})$ & 380 \\
Magnesium $(\mathrm{Mg})$ & 1222 \\
Potassium $(\mathrm{K})$ & 386.5 \\
Strontium $(\mathrm{Sr})$ & 6.456 \\
Chloride $(\mathrm{Cl})$ & 18520 \\
Bicarbonate $\left(\mathrm{HCO}_{3}\right)$ & 148 \\
Sulphate $\left(\mathrm{SO}_{4}\right)$ & 2000 \\
\hline
\end{tabular}

\subsection{Apparatus and Methods}

\subsubsection{Surface Tension Measurement}

The surface tension of the surfactant solution against air was investigated at $80{ }^{\circ} \mathrm{C}$ and $106{ }^{\circ} \mathrm{C}$ using IFT 700 equipment manufactured by "Vinci Technologies, France". The surface tension apparatus was used for determining the critical micelle concentration (CMC). For each measurement, the pendant drop method was applied, and the surface tension value was determined from the Laplace-Young equation based on the complete shape of the droplet [34]. The experimental set up of the IFT 700 is presented in Figure 1. The experimental setting was initially defined in the connected software portrayed in Figure 2. The densities of the drop and the bulk fluid were input into the software. The equipment contains a viewing chamber where the air was set as a bulk fluid and the surfactant solution as a drop fluid. The droplet was formed using a capillary needle which was placed on top of the testing cell. The detection limit was adjusted prior to generating a droplet. Once the droplet formed, its detection level was controlled by adjusting the brightness and the contrast level. The mounted camera analyzes the value, records, and captures the drop of the samples. 


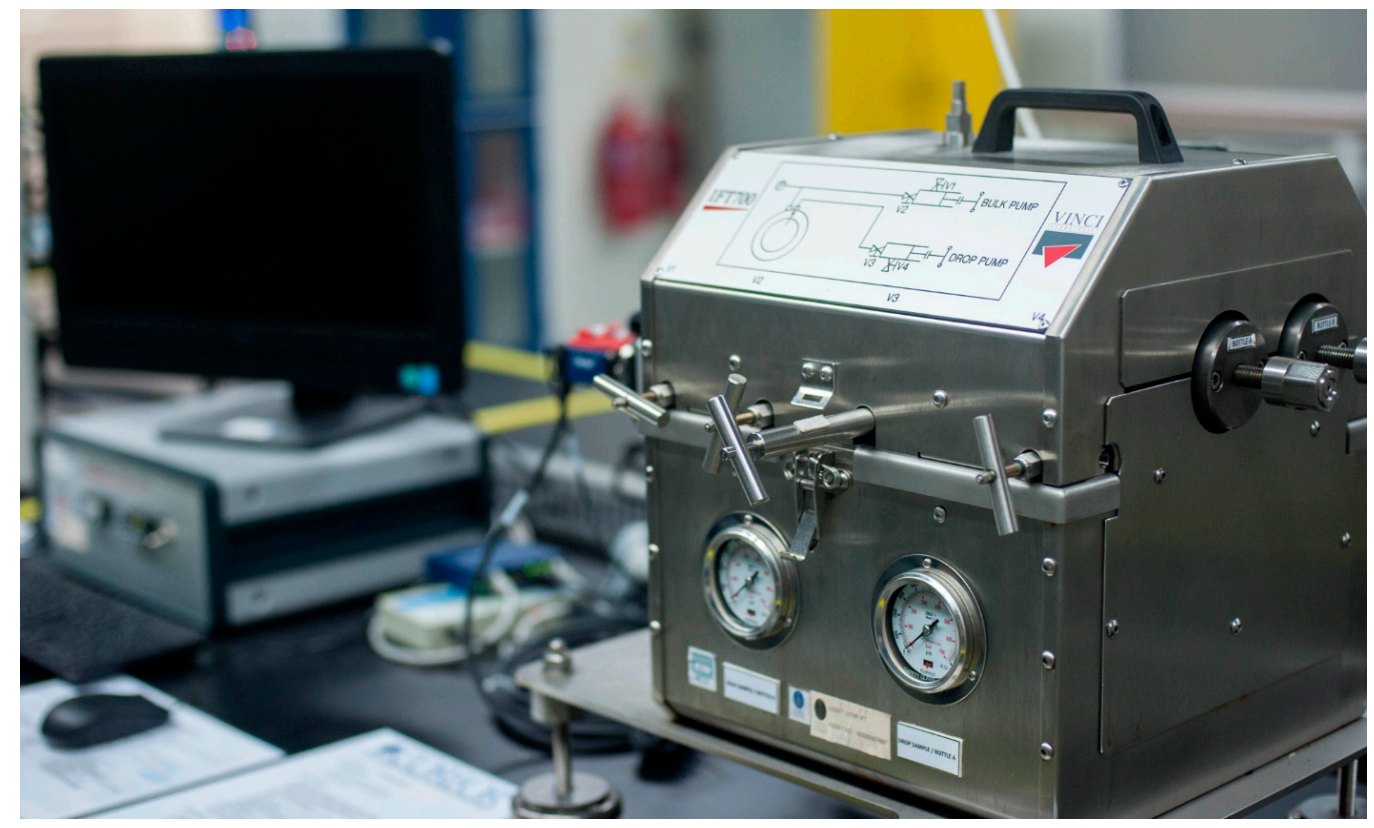

Figure 1. Set up for surface tension measurement using the Interfacial Tension "IFT 700".

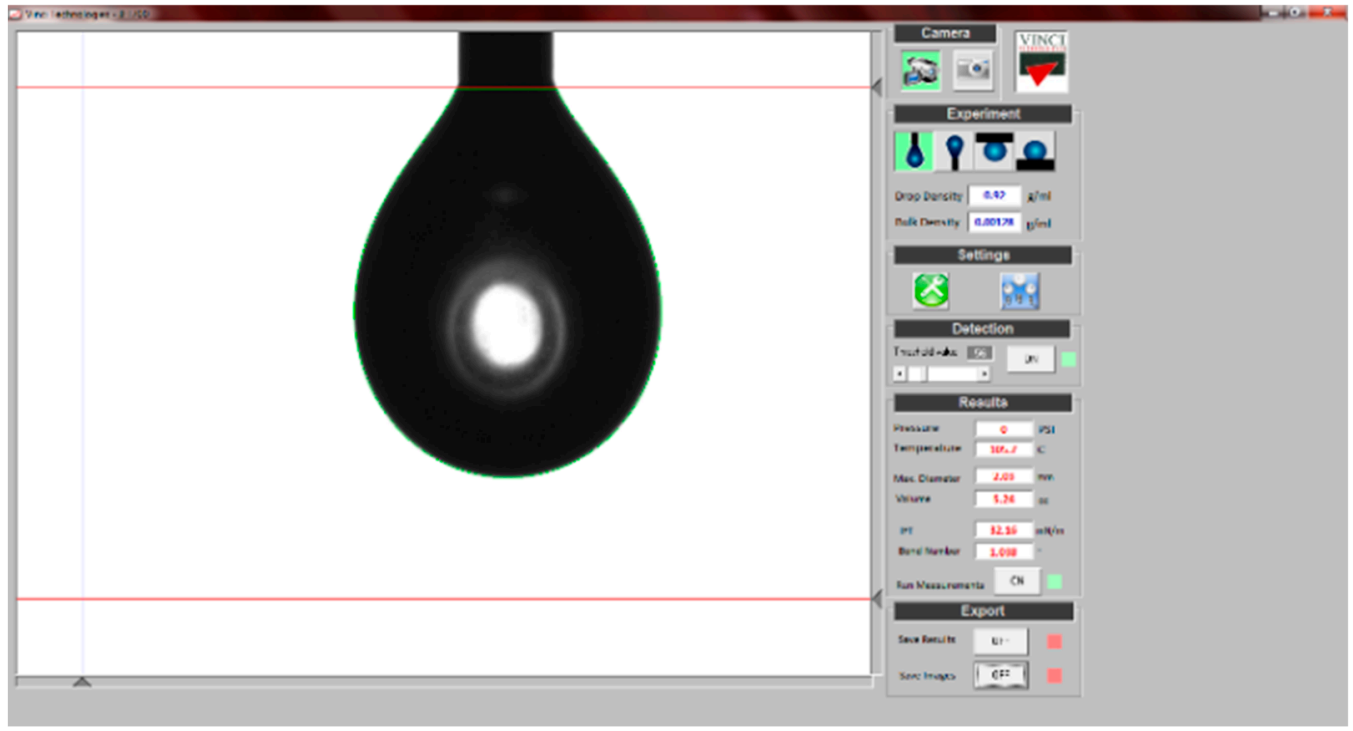

Figure 2. Surface tension measurement of the surfactant droplet using IFT 700 software.

\subsubsection{Interfacial Tension Measurement}

The interfacial tension (IFT) between crude oil and formulated surfactant solutions was measured using the spinning drop tensiometer SVT 20N "Dataphysics, Germany", shown in Figure 3. The spinning drop apparatus is used to measure the IFT between the surfactant solution and the crude oil. The purpose of using this apparatus is to evaluate the ability of surfactants to reduce the IFT between oil samples and the surfactant solution samples. The tested sample solution was placed in the capillary tube, and the drop of the crude oil was carefully injected. The capillary tube containing these two immiscible phases was then rotated at $3500 \mathrm{rpm}$. Each measurement was performed at $80^{\circ} \mathrm{C}$ and $106^{\circ} \mathrm{C}$. A constant temperature was achieved prior to each experiment. As the capillary spun at constant rotational velocity, the oil drop was deformed and elongated becoming cylindrical in shape depending on the IFT between the fluids [35]. Then, based on the spinning drop contours as well as the input parameters, such as the density of the oil and the surfactant solutions, temperature, and rotation of the system, the IFT value was determined and recorded automatically using the video measuring system until it 
remained stable. When the capillary tube spins, the centrifugal forces elongate the drop; all while the IFT suppresses this elongation in order to minimize the interfacial area by forming a perfectly spherical drop. For a cylindrical drop whose length is at least four times greater than its radius, the following expression (Equation (1)) is often used to calculate IFT:

$$
\sigma=\frac{r^{3} \cdot \omega^{2} \cdot \Delta \rho}{4}
$$

where $\sigma$ is the interfacial tension, $\Delta \rho$ is the density difference between the crude oil and the tested solutions, $\omega$ is the rotation rate, and $\mathrm{r}$ is the radius of the less dense drop [25,36].

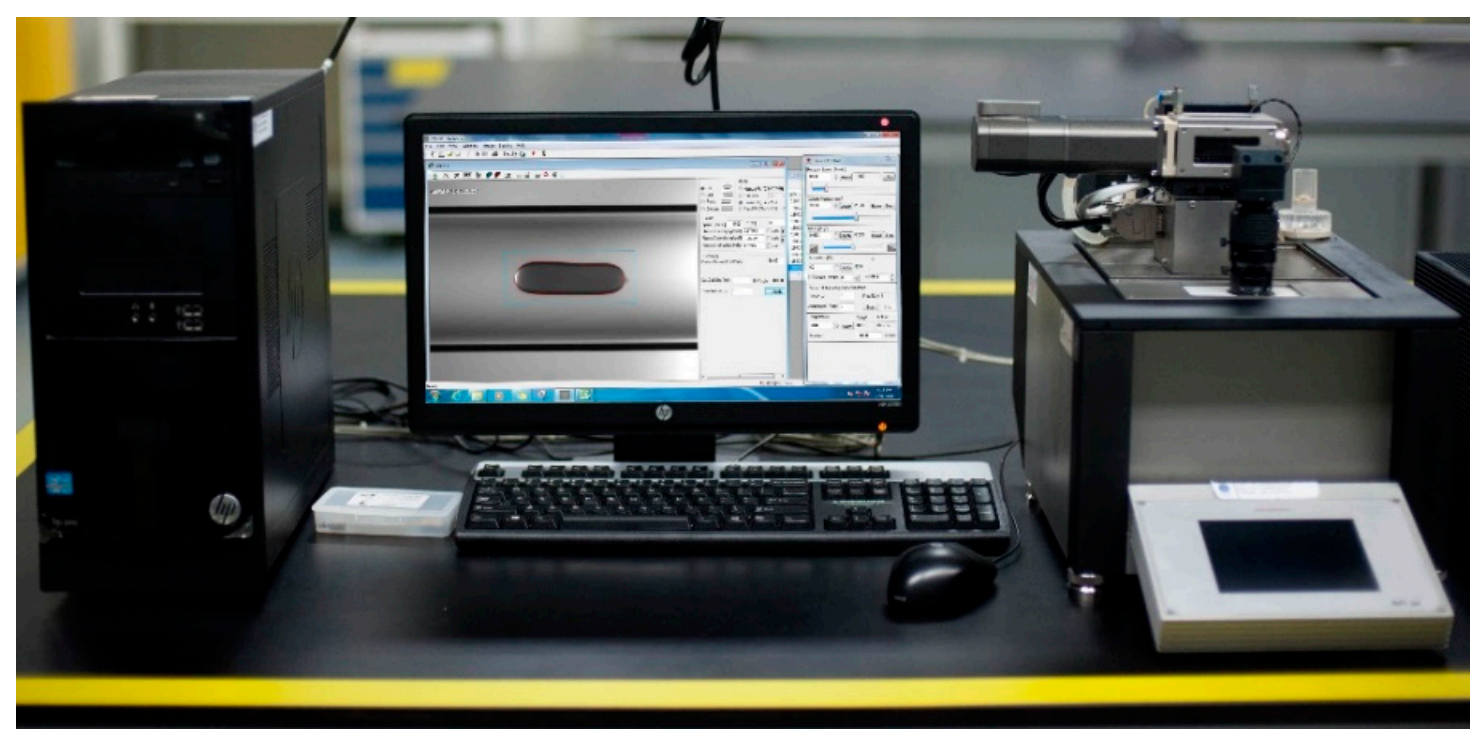

Figure 3. Spinning drop tensiometer SVT20N for IFT measurement.

\subsubsection{Surfactant Partitioning Test}

Partitioning experiments were conducted with a volume ratio of 10 between the aqueous surfactant solution and the crude oil, by adding $1 \mathrm{~mL}$ of crude oil and $10 \mathrm{~mL}$ of surfactant solution into a borosilicate glass tube. The glass tubes were thermally sealed to avoid any leakage that might occur. The tubes were shaken for 24 hours at high-temperature, giving enough time for the surfactant to partition from the aqueous phase into the oil phase and reach equilibrium. The aqueous solution was then transferred for analysis [8,20]. Oil and surfactant aqueous solution are two immiscible liquids, the ratio between their equilibrium concentrations is given by the partitioning or distribution coefficient $\mathrm{k}_{\mathrm{p}}$, and it can be measured according to Equation (2).

$$
K_{p}=\frac{C_{\text {oil }}}{C_{\text {water }}}=\frac{V_{\text {water }}}{V_{\text {oil }}}\left(\frac{C_{\text {water }, 0}-C_{\text {water }}}{C_{\text {water }}}\right)
$$

where $C_{\text {water }}$ and $C_{\text {oil }}$ are the surfactant concentrations in the aqueous phase and the oil phase, respectively, after the partitioning equilibrium has been reached, $\mathrm{V}_{\text {water }}$ is the volume of the aqueous phase with the initial surfactant concentration of $C_{w a t e r, 0}$, and $V_{\text {oil }}$ is the volume of the oil phase which is brought into contact with the aqueous phase $[8,19,20,37]$.

Surfactant Partitioning in the Pre-cmc Rregime

The equilibrium surface tension isotherms of APG at $80{ }^{\circ} \mathrm{C}$ and $106^{\circ} \mathrm{C}$ were prepared first. The surfactant solution was prepared in different concentrations below the CMC. Each surfactant concentration chosen was used as the initial surfactant concentration $C_{w a t e r, 0}$. The equilibrium surface tension isotherms for the surfactant solutions were used as reference curves to determine 
the final surfactant concentration in the aqueous phase $C_{\text {water }}$ after contact with the crude oil from their corresponding surface tension values. The partitioning coefficient $\mathrm{K}_{\mathrm{p}}$ was calculated using Equation $(2)[8,19,20]$.

\section{Surfactant Partitioning in the Post-cmc Regime}

In this case, the surfactant solution was prepared in different concentrations above the CMC. The test was conducted at $80^{\circ} \mathrm{C}$ and $106^{\circ} \mathrm{C}$, and the partitioning coefficient $\mathrm{K}_{\mathrm{p}}$ was also measured using Equation (2). This method requires measuring the final surfactant concentration in the aqueous phase $\mathrm{C}_{\text {water }}$ after contact with the crude oil. It was measured using an Agilent 1200 series high-performance liquid chromatography (HPLC) system with Evaporative Light Scattering Detector (ELSD) as a detector and acclaim surfactant plus $(3 \mu, 3.0 \times 150 \mathrm{~nm})$ Dionex bonded silica as a column. The conditions are set as follows: the column temperature is $40^{\circ} \mathrm{C}$, the flow rate is $0.8 \mathrm{~mL} / \mathrm{min}$ and the injection volume is $5 \mu \mathrm{L}$. Mobile phase $\mathrm{A}$ is $0.005 \mathrm{M}$ ammonium acetate ( $\mathrm{pH}$ 4.5) and mobile phase $\mathrm{B}$ is 80:20 ratio of methanol and acetonitrile. The detailed mobile phase gradient is described in Table 3.

Table 3. Details of mobile phase gradient.

\begin{tabular}{ccc}
\hline Time & Mobile Phase A & Mobile Phase B \\
\hline $0-2$ min & 85 & 15 \\
$20-35 \mathrm{~min}$ & 15 & 85 \\
$36-40 \mathrm{~min}$ & 85 & 15 \\
\hline
\end{tabular}

\section{Results and Discussion}

\subsection{Surface Tension Measurements (CMC Determination)}

CMC of APG was initially determined in order to investigate the surfactant concentration region containing optimum surface activity. This region is determined based on the surface tension values as the concentration increases. The surface tension profile as a function of surfactant concentration at a temperature of $80^{\circ} \mathrm{C}$ and $106^{\circ} \mathrm{C}$ is shown in Figure 4. It can be observed clearly that the surface tension of the surfactant solution sharply decreases with the increase of the surfactant concentration, indicating an increase in the surfactant surface activity. Subsequently, insignificant changes in the surface tension were observed when the surfactant concentration was increased. Micelles formation is indicated by the point in which the discontinuity in the plot took place. Based on the intersection of the two regression lines fitted on the upper and lower regions of the surface tension values of the curve, CMC of APG was found to be approximately $0.19 \mathrm{wt} \%$ and $0.17 \mathrm{wt} \%$ at $80^{\circ} \mathrm{C}$ and $106{ }^{\circ} \mathrm{C}$, respectively. Above the $\mathrm{CMC}$, the surface activity of APG remained almost the same whereby the surfactant molecules were distributed as monomers in the aqueous phase, forming micelles, and creating a surfactant layer on the surface [38]. A lower CMC of APG was obtained at a higher temperature, demonstrating that surfactant monomers have higher mobility to cover and saturate the surface by their self-arrangement and thus form micelles [39]. 


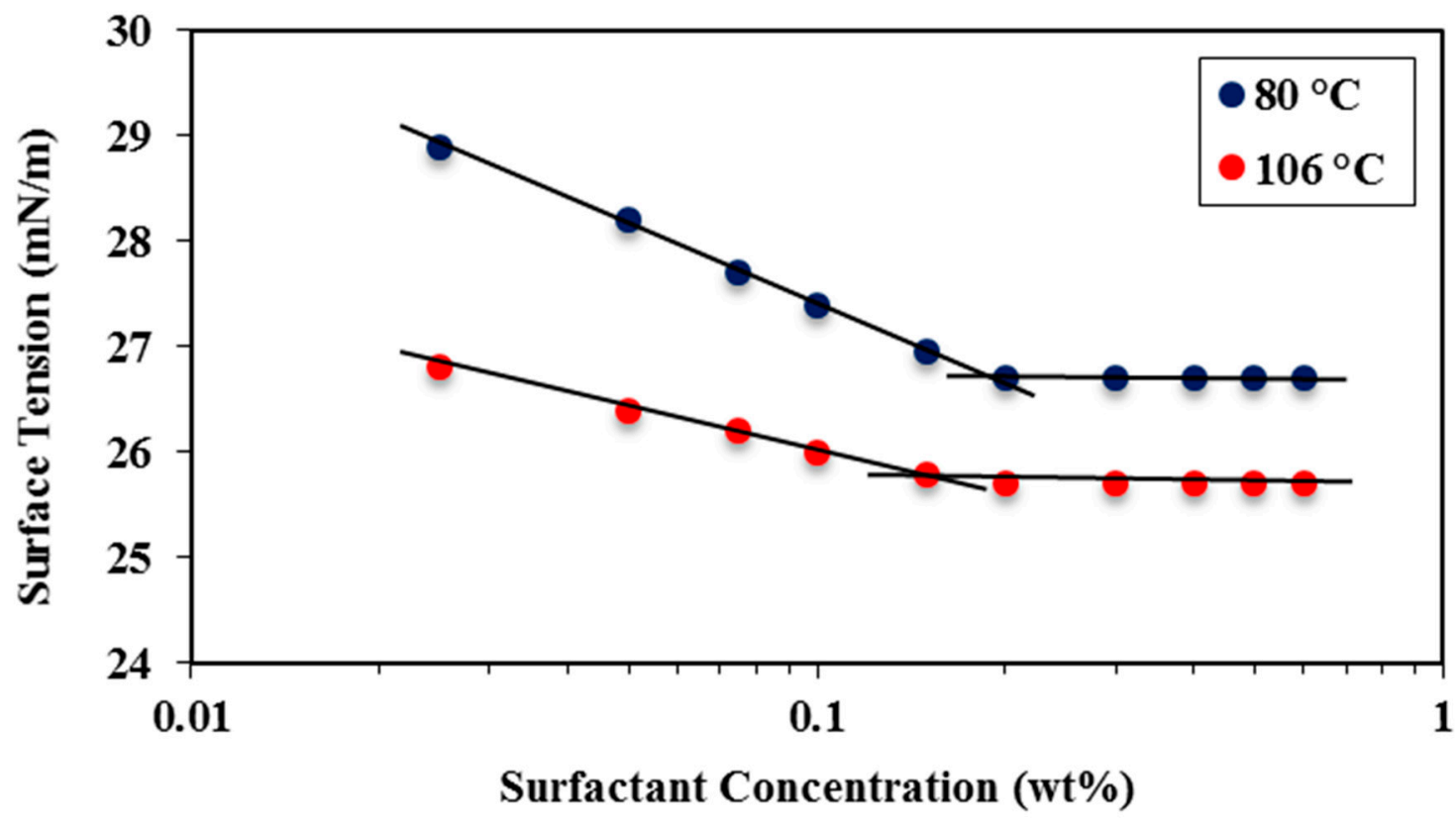

Figure 4. Surface tension of APG as a function of the surfactant concentration at $80{ }^{\circ} \mathrm{C}$ and $106^{\circ} \mathrm{C}$.

\subsection{Interfacial Tension of Crude Oil in the Presence of APG}

The injection of the surfactant solution contributes to mobilizing the residual oil by significantly reducing the oil-water interfacial tension. Thus, increasing the capillary number $\left(\mathrm{N}_{\mathrm{c}}\right)$ to the required range for the efficient performance of the oil recovery process [40,41]. The change in the oil droplet size with time is photographed in Figure 5. The surface of the drops was very smooth and as predicted theoretically, the drops were elongated along the horizontal axis of rotation with increasing speed of rotation. The shape of the oil droplet expanded continuously with time breaking at the $40 \mathrm{~min}$ mark as described in Figure 5. The final reading was taken when the droplet stabilized after $60 \mathrm{~min}$.

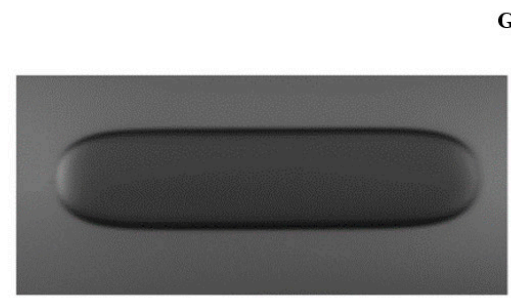

10 minutes

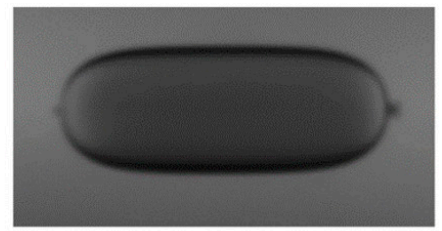

60 minutes
Geometry Vertical Scale [89.85 Pixel/mm]

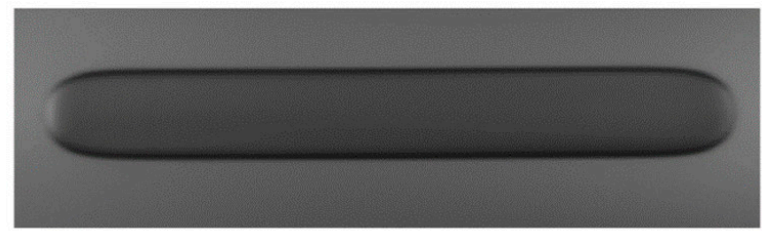

30 minutes

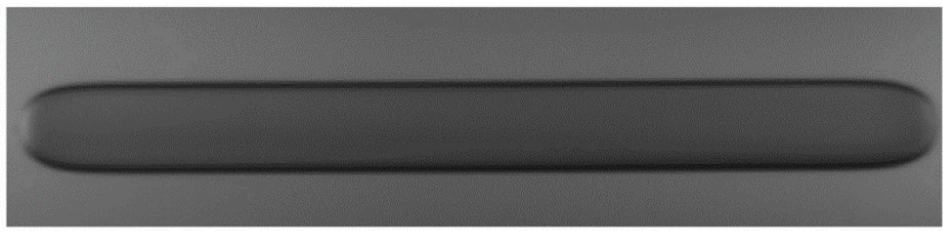

40 minutes

Figure 5. Photographs illustrating the change of oil droplet size with time at $106^{\circ} \mathrm{C}$.

The effects of the APG surfactant on the interfacial tension between the crude oil and the aqueous phase was investigated at different surfactant concentrations and temperatures. It can be seen from Figure 6 that at a low surfactant concentration, the IFT decreases with the increase of surfactant concentration for each temperature. The IFT values were initially $22.6 \mathrm{mN} / \mathrm{m}$ and $12.5 \mathrm{mN} / \mathrm{m}$ at $80^{\circ} \mathrm{C}$ 
and $106^{\circ} \mathrm{C}$, respectively. The IFT values decreased sharply reaching the lowest values in the profile at $0.05 \mathrm{wt} \%$, which were approximately $0.38 \mathrm{mN} / \mathrm{m}$ and $0.18 \mathrm{mN} / \mathrm{m}$ at $80^{\circ} \mathrm{C}$ and $106^{\circ} \mathrm{C}$, respectively. Then, the IFT increased gradually when increasing the concentration of APG and finally attained a constant trend. At a lower surfactant concentration range, the surfactant molecules preferably adsorb at the interface between oil and water from the aqueous solution and, therefore, the interfacial tension of the solution decreased rapidly. Subsequently, the IFT passes through a minimum value where the interface becomes saturated with the surfactant monomers. Once the absorbed surfactant molecules on interface reach adsorption saturation, the surfactant molecules would stop adsorbing; hence, a constant IFT value was kept $[9,22,40]$. The temperature has a significant influence on IFT, where the increase in the temperature from $80^{\circ} \mathrm{C}$ to $106^{\circ} \mathrm{C}$ exhibited a considerable IFT reduction. Temperature generally has an influence on the solubility of the surfactant solution and changes the interaction energy of the head and tail groups. The increase in the temperature can increase the solubility of the surfactants hydrophobic tail in the water and move the surfactant to the oil-water interface resulting in a decrease in the IFT as demonstrated in Figure 6 [42].

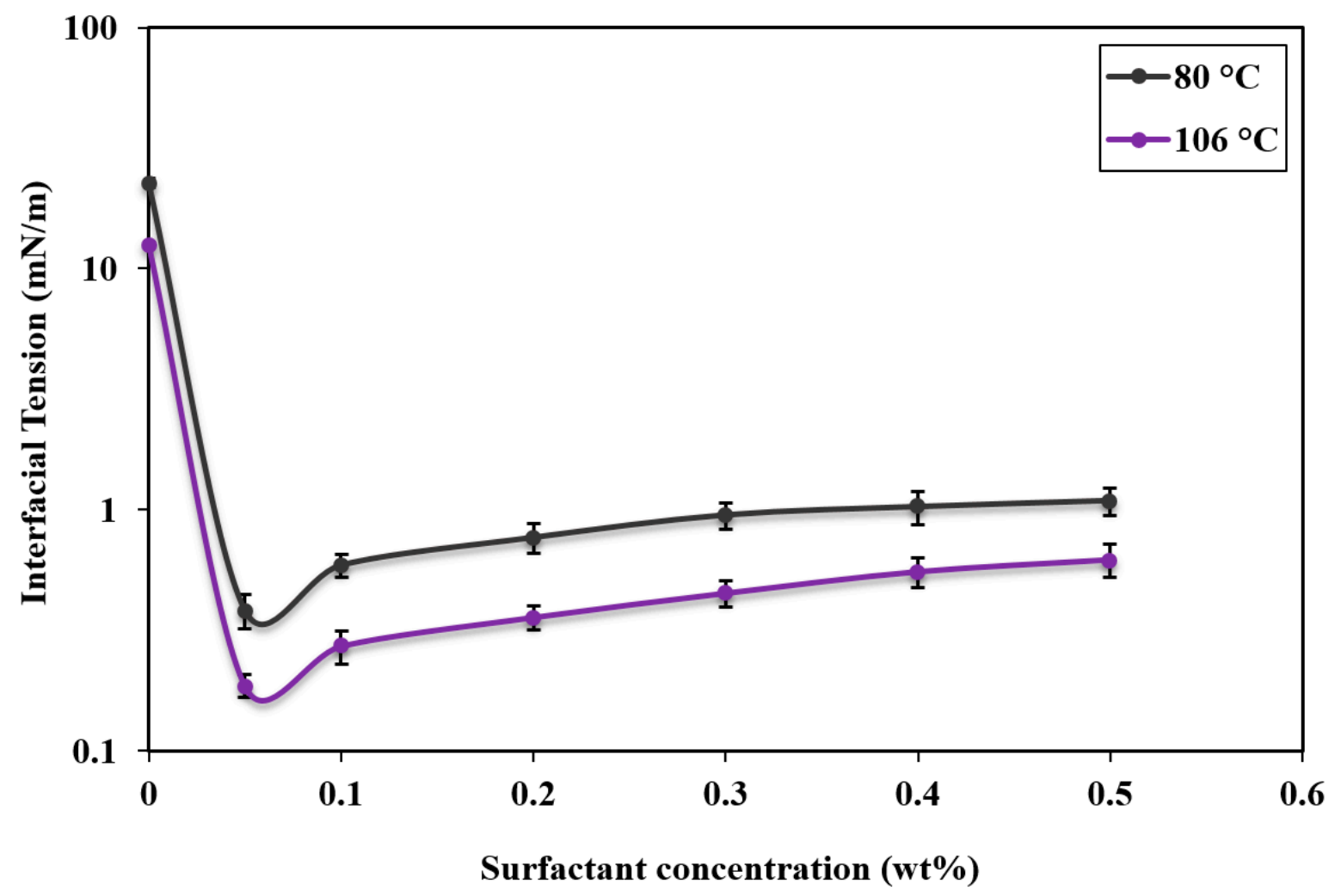

Figure 6. Interfacial tension of APG as a function of the surfactant concentration at $80{ }^{\circ} \mathrm{C}$ and $106^{\circ} \mathrm{C}$.

\subsection{Surfactant Partitioning in the Pre-cmc Regime}

The partitioning of APG in the pre-cmc regime was studied by investigating the effect of the surfactant concentration and temperature on the surfactant partitioning between crude oil and water. Figure 7 shows the equilibrium surface tension isotherm for APG. This curve was used as a reference curve to determine the initial concentration of the aqueous solutions $C_{w a t e r, 0}$ as well as the final concentration in the aqueous phase $C_{w a t e r}$ after contact with the crude oil, and therefore, the partitioning coefficient was calculated according to Equation (2). Correspondingly, the partitioning coefficient for APG was determined. The measurements were repeated several times, and the reading was taken 10 times for each sample. The range of error for each surface tension measurement at $80^{\circ} \mathrm{C}$ and $106^{\circ} \mathrm{C}$ is portrayed below in Figure 8 . 


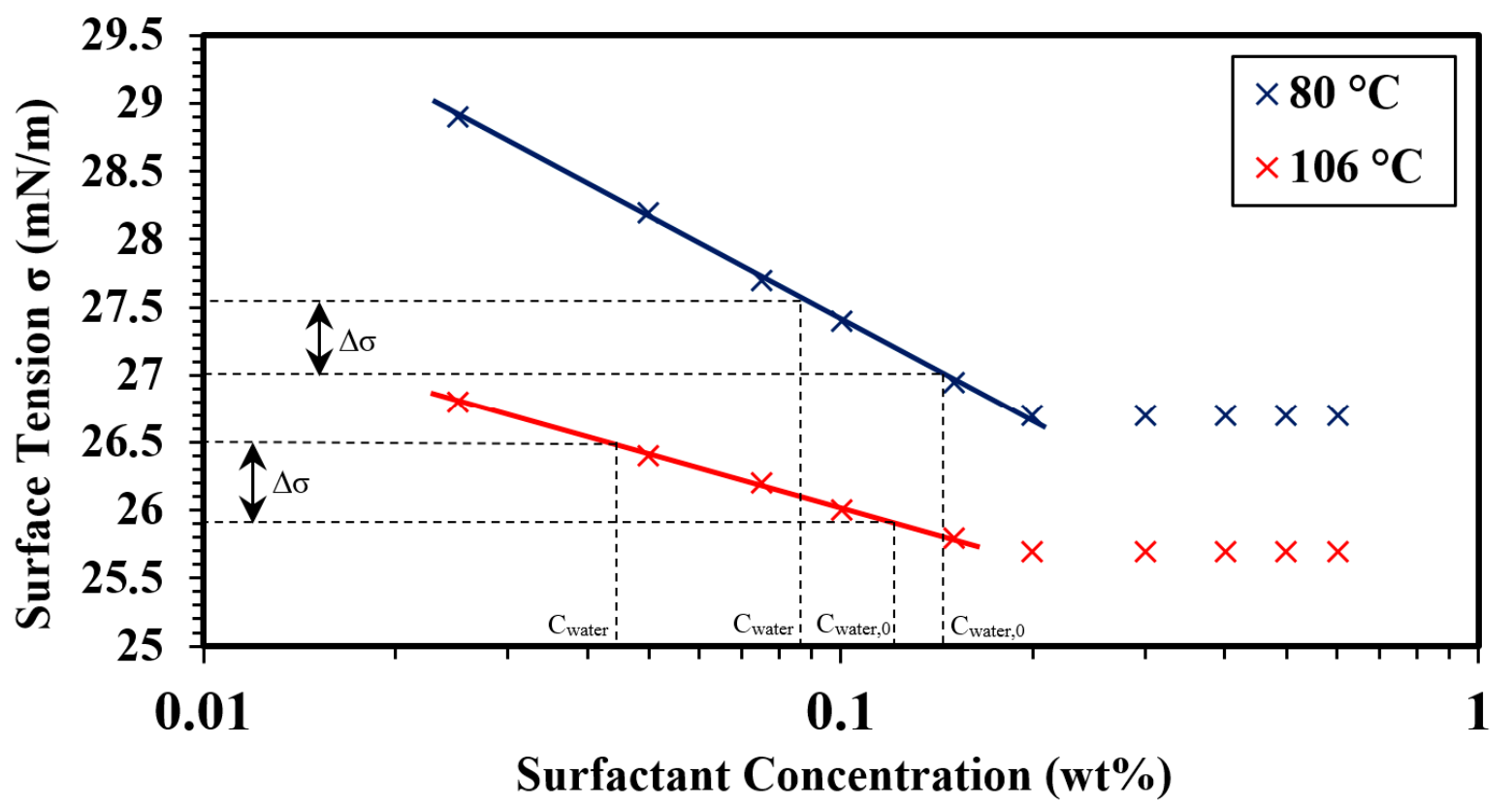

Figure 7. Determination of APG concentration in the aqueous phase $\left(\mathrm{C}_{\text {water }}\right)$ after contact with the oil phase using the equilibrium surface tension isotherm at $80^{\circ} \mathrm{C}$ and $106^{\circ} \mathrm{C} . \Delta \sigma$ is the difference between the surface tension values of the surfactant solutions before $\left(C_{\text {water, } 0}\right)$ and after contact with the oil phase $\left(C_{\text {water }}\right)$.

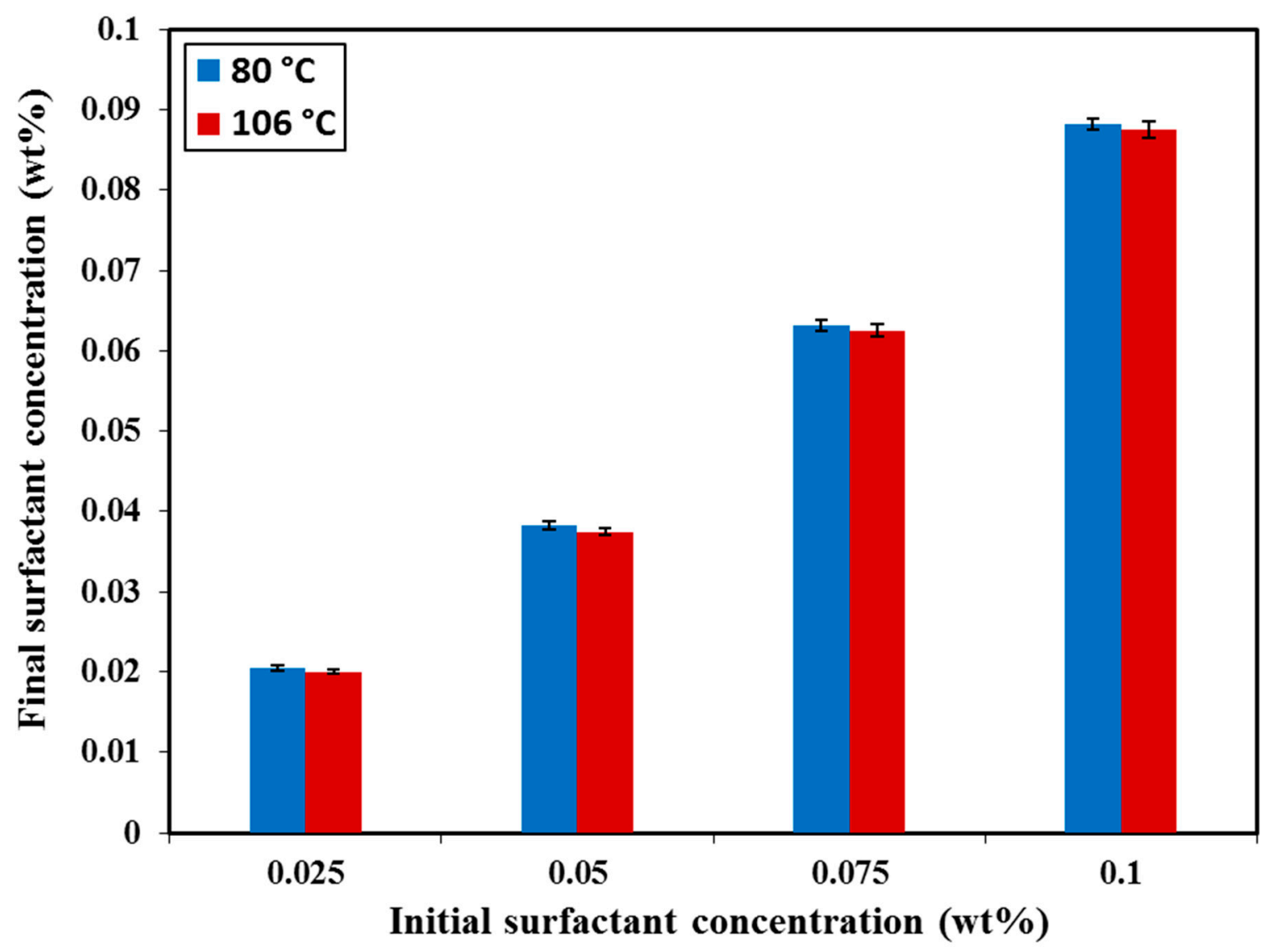

Figure 8. The range of error for each surface tension measurement at $80^{\circ} \mathrm{C}$ and $106^{\circ} \mathrm{C}$. 
Figure 9 shows the partitioning coefficient of APG calculated using Equation (2) as a function of surfactant concentration and temperature in the pre-cmc region. From the graph, it can be seen that the partitioning coefficient of APG increases in the range between $0.025 \mathrm{wt} \%$ and $0.05 \mathrm{wt} \%$. The value then decreases as the surfactant concentration increases with an approximate value of 1.3 at $0.1 \mathrm{wt} \%$ for both temperatures recorded. The partitioning coefficient can be directly related to the IFT in order to explain the behavior of the partitioning coefficient results. The highest partitioning amount was observed at $0.05 \mathrm{wt} \%$ corresponding to the lowest IFT value, as seen in Figure 6 . This is due to the high partitioning rate of the surfactant molecules, which allows them to cover a wider surface of oil resulting in a sharp decrease in the IFT. The partitioning decreases gradually with the increase of surfactant concentration above $0.05 \mathrm{wt} \%$, showing a lower intensity of surfactant migration to the water-oil interface causing the IFT to increase. These results are in good agreement with the obtained IFT results.

The effect of temperature on the partitioning of APG was also demonstrated in Figure 9. It can be noticed that the partitioning coefficient values at $106^{\circ} \mathrm{C}$ were higher than their counterparts at $80^{\circ} \mathrm{C}$. At $80^{\circ} \mathrm{C}$, the partitioning rate of APG was lower due to the lower surfactant solubility [25]. Increasing the temperature influences the solubility and the interaction energies of the APG's head and tail groups in the aqueous solution, as it's directly related to the formation of the micelle and interfacial tension reduction [43]. In line with the IFT results described in Figure 6, the increase of temperature increases the partitioning rate of the surfactant molecules into the water-oil interface, causing a reduction in IFT. The reduction of IFT while increasing the temperature occurs due to the decrease in the viscosity of the oil, leading to the enhancement of the surfactant partitioning to the interface [42].

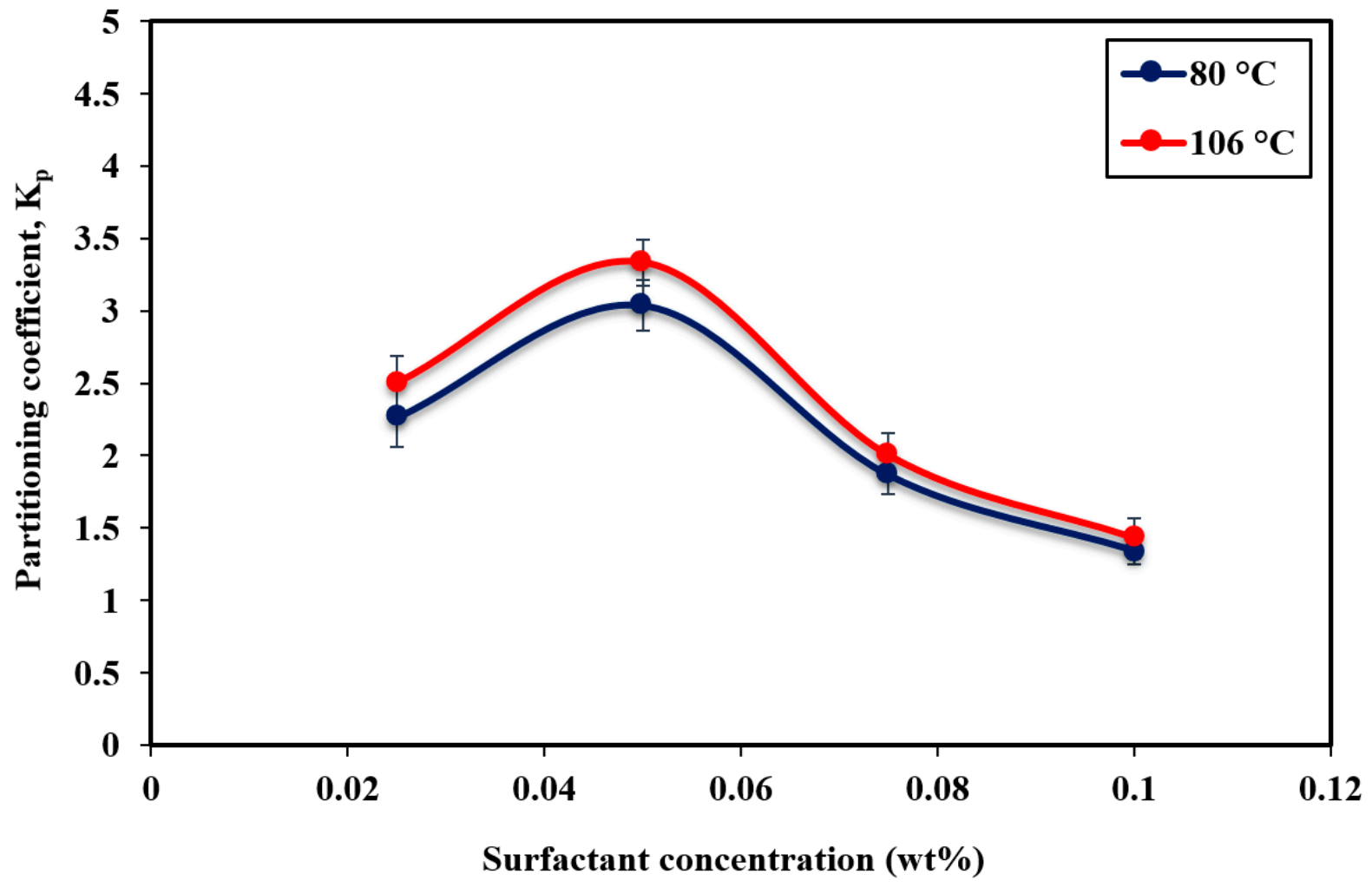

Figure 9. Partitioning coefficient $(\mathrm{Kp})$ vs. the surfactant concentration in the pre-cmc region.

\subsection{Surfactant Partitioning in the Post-cmc Regime}

The corresponding peaks of APG in the obtained chromatograph using HPLC are demonstrated in Figure 10. Noteworthy, the first step for measuring the surfactant concentration using HPLC is to obtain a calibration curve. The straight line in Figure 11 demonstrates the standard curve of APG based on the HPLC method; indicating that the chromatographic integral area exhibits a good linear relationship with the concentration of APG in the range of $0.1-0.6 \mathrm{wt} \%$. 


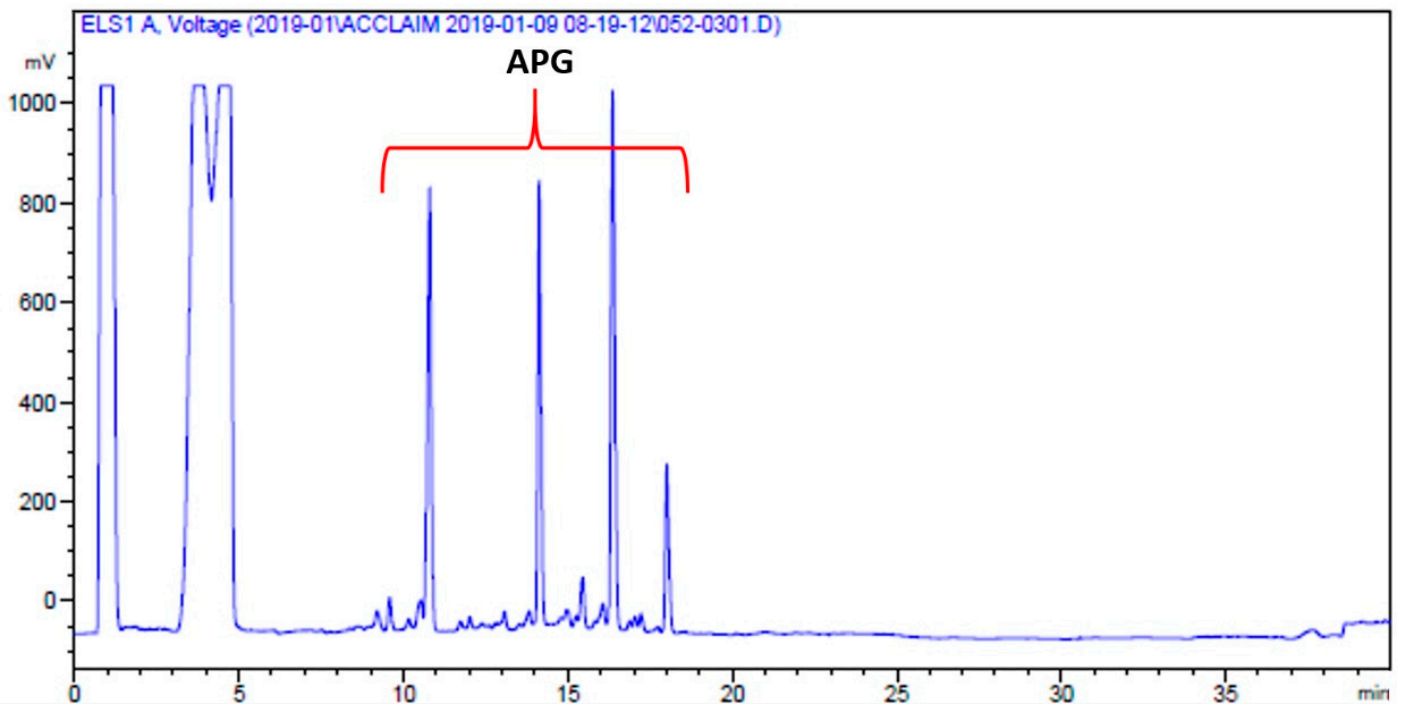

Figure 10. Chromatogram of APG indicating the peaks used for the analysis.

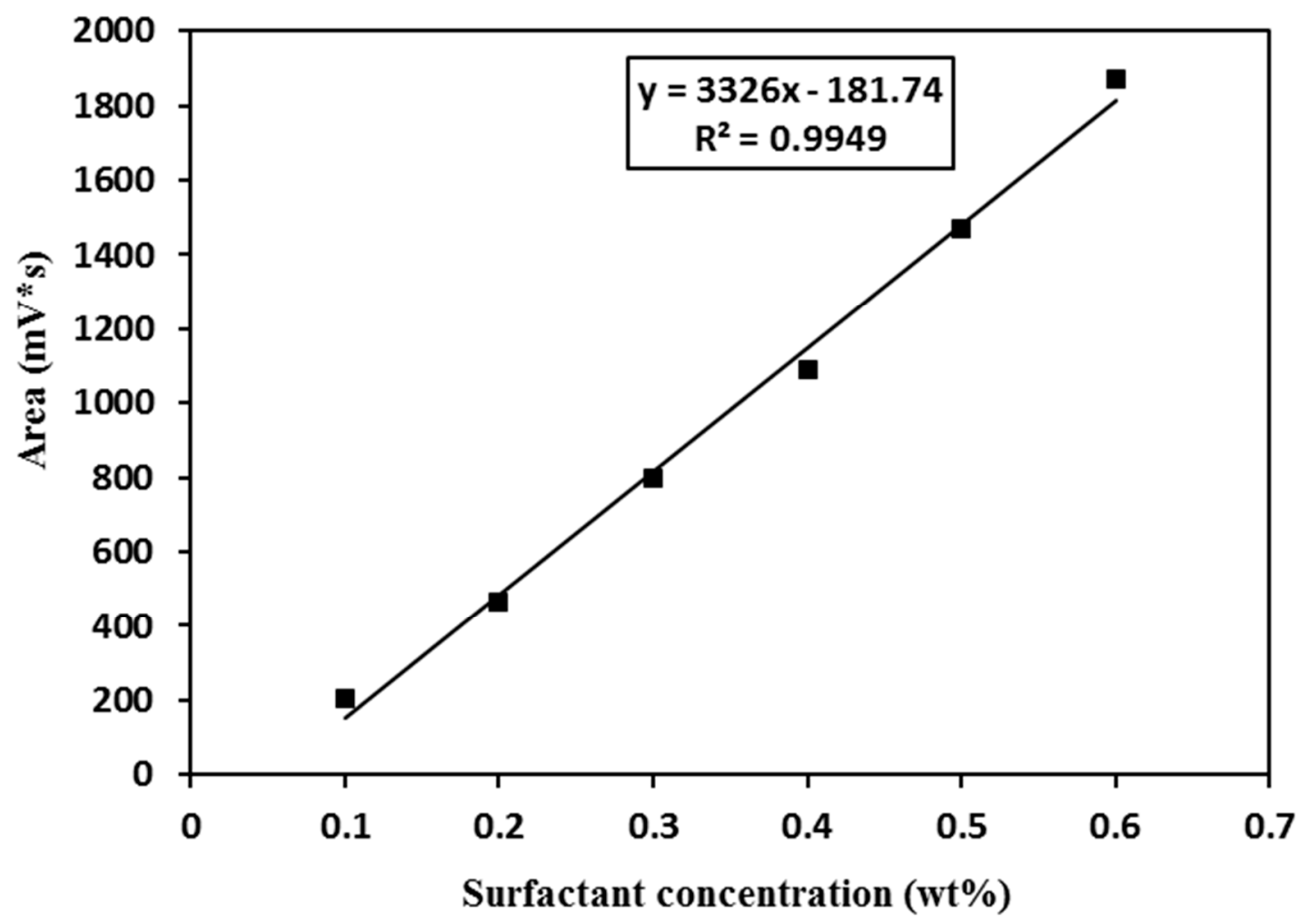

Figure 11. Standard curve based on the HPLC method for measuring the APG concentration.

The partitioning of APG in the post-cmc regime was investigated by considering the effect of the surfactant concentration and temperature. The initial surfactant concentration range was chosen above the $\mathrm{CMC}$ values at $80^{\circ} \mathrm{C}$ and $106^{\circ} \mathrm{C}$. The final surfactant concentration $\mathrm{C}_{\text {water }}$ after contact with the crude oil was measured based on the standard curve shown in Figure 11 and the partitioning coefficient was calculated according to Equation (2). The measurement for each sample using HPLC was repeated twice with no significant differences observed between the results. The results for the surfactant partitioning coefficient of APG in the post-cmc region are illustrated in Figure 12. It can be noticed that the partitioning coefficient of APG was high at $0.2 \mathrm{wt} \%$ and was about 0.8 and 1.0 at $80{ }^{\circ} \mathrm{C}$ and $106^{\circ} \mathrm{C}$, respectively. However, the partitioning coefficient decreases sharply as the surfactant concentration 
increases. At $0.5 \mathrm{wt} \%$, the partitioning coefficient was very low, around 0.143 and 0.045 at $80{ }^{\circ} \mathrm{C}$ and $106{ }^{\circ} \mathrm{C}$ respectively. This effect is attributed to that above CMC; surfactant micelles stop increasing as the surfactant concentration increases causing a lower partitioning rate of the surfactant molecules into the water-oil interface. This would result in an increase in IFT. [22,40,44]. The partitioning coefficient outcomes agree with the IFT results shown in Figure 6.

Furthermore, Figure 12 shows that the partitioning coefficient of APG is higher at $106^{\circ} \mathrm{C}$ than it is at $80{ }^{\circ} \mathrm{C}$. At $106^{\circ} \mathrm{C}$, the IFT decrease was observed as in Figure 6, showing more partitioned surfactant molecules in the water-oil interface than at $80^{\circ} \mathrm{C}$. These results are attributed to the fact that solvents expand more at higher temperatures, which increases the surface area at the oil-water interface. Consequently, the interface will possess more adsorption sites and, in addition, the surfactant mobility (partitioning) and interactions at the water-oil interface will be enhanced simultaneously $[9,25,27,42]$.

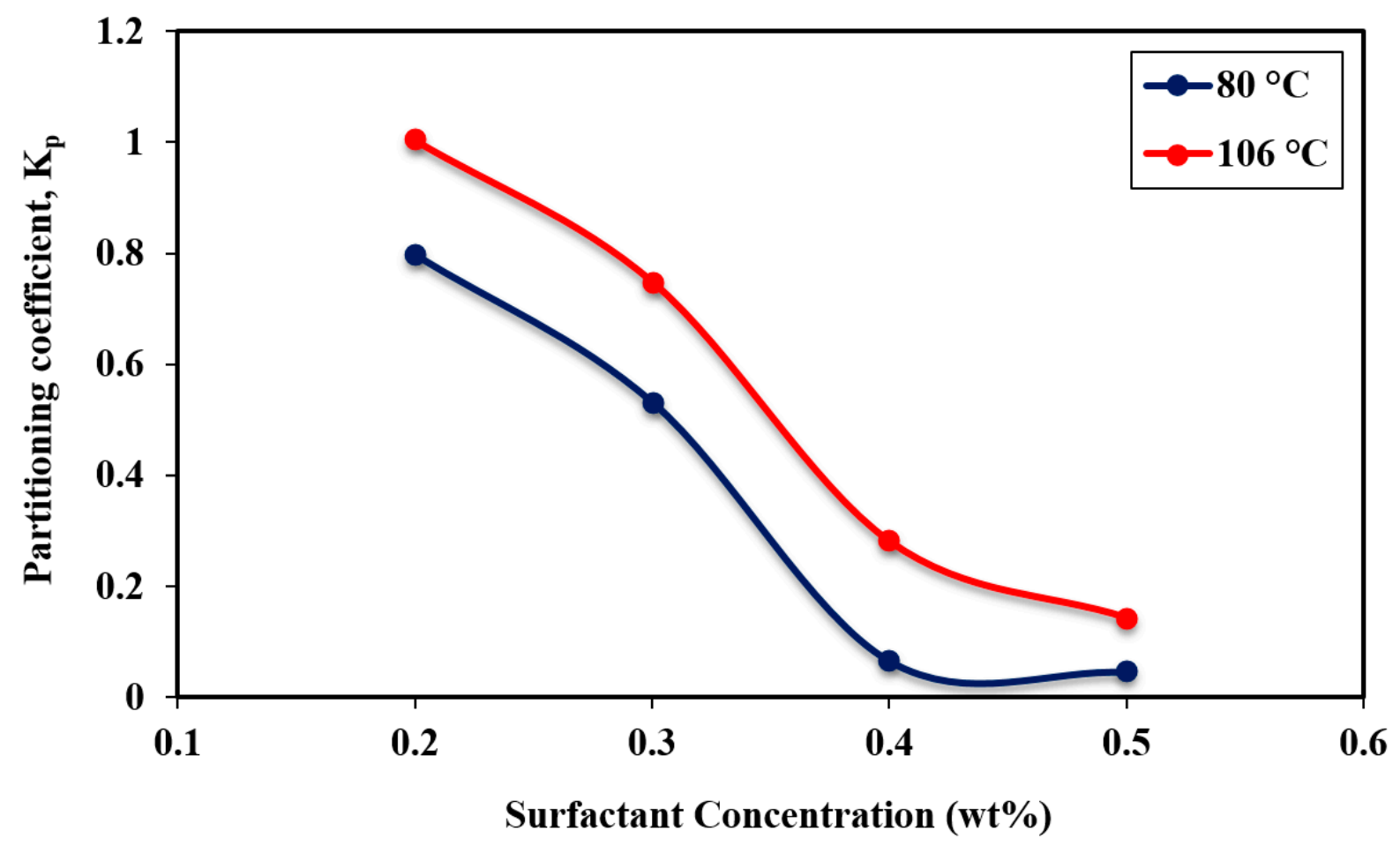

Figure 12. Partitioning coefficient $\left(K_{\mathrm{p}}\right)$ vs. the surfactant concentration in the post-cmc region.

\section{Conclusions}

The partitioning coefficient $\left(\mathrm{K}_{\mathrm{p}}\right)$ was determined in order to investigate the partitioning of the nonionic surfactant Alkylpolyglucoside (APG) in pre-cmc and post-cmc regimes. The partitioning of APG at varying surfactant concentrations and temperatures was studied by using surface tension measurements in the pre-cmc regime and high-performance liquid chromatography (HPLC) in the post-cmc regime. Surface tension (ST) and interfacial tension (IFT) tests were performed prior to the partitioning experiments via pendant and spinning drop tests respectively. The following outcomes were obtained from this study:

1. Based on the surface tension measurements for $A P G$, the $C M C$ was found to be around $0.19 \mathrm{wt} \%$ and $0.17 \mathrm{wt} \%$ at $80^{\circ} \mathrm{C}$ and $106^{\circ} \mathrm{C}$, respectively.

2. The IFT reduction in the oil/water system was significantly affected by the increase of surfactant concentration and temperature. The lowest IFT value in the IFT profile was at $0.05 \mathrm{wt} \%$, which was about $0.38 \mathrm{mN} / \mathrm{m}$ and $0.18 \mathrm{mN} / \mathrm{m}$ at $80^{\circ} \mathrm{C}$ and $106^{\circ} \mathrm{C}$, respectively. Also, the temperature had a significant influence on the IFT, where the increase in temperature from $80^{\circ} \mathrm{C}$ to $106^{\circ} \mathrm{C}$ showed a considerable IFT reduction. 
3. The partitioning test results for APG in the pre-cmc regime with correspondence to the IFT results showed that the partitioning coefficient increased below $0.05 \mathrm{wt} \%$. Beyond this concentration, the increase of surfactant concentration caused the partitioning coefficient to decrease. The increase of temperature from $80^{\circ} \mathrm{C}$ to $106^{\circ} \mathrm{C}$ increases the partitioning rate of surfactant molecules into the water-oil interface causing a reduction in IFT. The highest partitioning amount was observed at $0.05 \mathrm{wt} \%$ corresponding to the lowest IFT value and it was about 3 and 3.3 at $80{ }^{\circ} \mathrm{C}$ and $106^{\circ} \mathrm{C}$, respectively.

4. The study of the partitioning of APG in the post-cmc regime illustrated that above CMC, the partitioning coefficient decreases as thr surfactant concentration increases, indicating that not all surfactant molecules are at the interface which results in an increase in IFT. The partitioning coefficient value in the post-cmc regime was lower than that in the pre-cmc regime. The effect of temperature on the partitioning in the post-cmc region has the same impact as in the pre-cmc region, where additional partitioned surfactant molecules arise at the water-oil interface at $106^{\circ} \mathrm{C}$.

Author Contributions: A.F.B. wrote this paper, designed and performed the experiments, and analyzed the data; K.A.E. supervised this study, contributed to performing the experiments, provided materials and instruments, and also edited the manuscript; M.S.A. assisted in the data analysis, provided technical support during the experiments, and revised the manuscript; J.A.B.M.S. assisted in the data analysis, and revised the manuscript; S.M.M. contributed in providing the materials and instruments, and also edited the manuscript; L.W.E. assisted in revising the manuscript.

Funding: Authors greatly appreciate the financial support from the Universiti Teknologi PETRONAS. The authors gratefully acknowledge PETRONAS Research Sdn Bhd for providing the funding (under 0153CB-013 project), chemicals, laboratory facilities, and services.

Conflicts of Interest: The authors declare no conflict of interest.

\section{References}

1. Shafie, A.; Yahya, N.; Kashif, M.; Zaid, H.M.; Soleimani, H.; Alnarabiji, M.S. The Band Structures of Single-Walled Carbon Nanotubes and ZnO Nanoparticles Used for Oil Recovery in Water Flooding System. J. Nano Res. 2013, 26, 101-110. [CrossRef]

2. Alnarabiji, M.S.; Yahya, N.; Shafie, A.; Solemani, H.; Chandran, K.; Bee, S.; Hamid, A.; Azizi, K. The Influence of Hydrophobic Multiwall Carbon Nanotubes Concentration on Enhanced Oil Recovery. Procedia Eng. 2016, 148, 1137-1140. [CrossRef]

3. Adil, M.; Lee, K.; Zaid, H.M.; Latiff, N.R.A.; Alnarabiji, M.S. Experimental study on electromagnetic-assisted $\mathrm{ZnO}$ nanofluid flooding for enhanced oil recovery (EOR). PLoS ONE 2018, 13, 1-18. [CrossRef] [PubMed]

4. Alnarabiji, M.S.; Yahya, N.; Hamid, S.B.A.; Azizli, K.A.; Kashif, M.; Qureshi, S.; Alqasem, B. The Role of Surface Area of ZnO Nanoparticles as an Agent for some Chemical Reactions. Defect Diffus. Forum 2014, 354, 201-213. [CrossRef]

5. Belhaj, A.F.; Elraies, K.A.; Janjuhah, H.T.; Tasfy, S.F.H.; Yahya, N.; Abdullah, B.; Umar, A.A.; Ghanem, O.B.; Alnarabiji, M.S. Electromagnetic waves-induced hydrophobic multiwalled carbon nanotubes for enhanced oil recovery. J. Pet. Explor. Prod. Technol. 2019, 4-7. [CrossRef]

6. Demirbas, A.; Alsulami, H.E.; Hassanein, W.S. Utilization of Surfactant Flooding Processes for Enhanced Oil Recovery (EOR). Pet. Sci. Technol. 2015, 33, 1331-1339. [CrossRef]

7. Ahmed, S.; Elraies, K.A.; Hashmet, M.R.; Alnarabiji, M.S. Empirical modeling of the viscosity of supercritical carbon dioxide foam fracturing fluid under different downhole conditions. Energies 2018, 11, 782. [CrossRef]

8. Kedar, V.; Bhagwat, S.S. Effect of salinity on the IFT between aqueous surfactant solution and crude oil. Pet. Sci. Technol. 2018, 36, 835-842. [CrossRef]

9. Mosayebi, A.; Angaji, M.T.; Khadiv-parsi, P. The effect of temperature on the interfacial tension between crude oil and ethoxylated nonylphenols. Pet. Sci. Technol. 2016, 34, 1315-1322. [CrossRef]

10. Alnarabiji, M.S.; Yahya, N.; Nadeem, S.; Adil, M.; Baig, M.K.; Ghanem, O.B.; Azizi, K.; Ahmed, S.; Maulianda, B.; Klemeš, J.J.; et al. Nanofluid enhanced oil recovery using induced ZnO nanocrystals by electromagnetic energy: Viscosity increment. Fuel 2018, 233, 632-643. [CrossRef] 
11. Thomas, S.; Ali, S.M.F. Micellar Flooding and ASP-Chemical Methods for Enhanced Oil Recovery. In Proceedings of the Annual Technical Meeting, Calgary, AB, Canada, 14-18 June 1999.

12. Alnarabiji, M.S.; Yahya, N.; Bee Abd Hamid, S.; Azizli, K.A.; Shafie, A.; Solemani, H. Microwave Synthesis of ZnO Nanoparticles for Enhanced Oil Recovery. Adv. Mater. Res. 2014, 1024, 83-86. [CrossRef]

13. Chen, F.; Mccool, C.S.; Green, D.W.; Willhite, G.P. Experimental and Modeling Study of the Transport of Chromium Acetate Solutions Through Carbonate Rocks. SPE J. 2010. [CrossRef]

14. Sandersen, S.B. Enhanced Oil Recovery with Surfactant Flooding. Ph.D. Thesis, Technical University of Denmark, Kongens Lyngby, Denmark, 2012; pp. 1-162.

15. Hirasaki, G.J.; Miller, C.A.; Puerto, M. Recent Advances in Surfactant EOR. Soc. Pet. Eng. 2011. [CrossRef]

16. Mccool, C.S.; Panneswar, R.; Willhite, G.P. Interpretation of Differential Pressure in Laboratory Surfactant/Polymer Displacements. Soc. Pet. Eng. J. 1983, 791-803. [CrossRef]

17. Myers, D. Surfactant Science and Technology Surfactant Science; John Wiley \& Sons, Inc.: Hoboken, NJ, USA, 2006; ISBN 9780471680246.

18. Belhaj, A.F.; Elraies, K.A.; Mahmood, S.M.; Zulkifli, N.N.; Akbari, S.; Hussien, O.S. The effect of surfactant concentration, salinity, temperature, and $\mathrm{pH}$ on surfactant adsorption for chemical enhanced oil recovery: A review. J. Pet. Explor. Prod. Technol. 2019, 1-13. [CrossRef]

19. Ravera, F.; Ferrari, M.; Liggieri, L.; Miller, R.; Passerone, A. Measurement of the Partition Coefficient of Surfactants in Water/Oil Systems. Langmuir 1997, 13, 4817-4820. [CrossRef]

20. Catanoiu, G.; Carey, E.; Patil, S.R.; Engelskirchen, S.; Stubenrauch, C. Partition coefficients of nonionic surfactants in water/n-alkane systems. J. Colloid Interface Sci. 2011, 355, 150-156. [CrossRef] [PubMed]

21. Young, T.J.; Nelson, C.W.; Lyons-bell, C.; Moore, J.D. Fluid Phase Equilibria High temperature and pressure water/oil interfacial tension benchmark data for the Ninth Industrial Fluid Properties Simulation Challenge. Fluid Phase Equilib. 2018, 476, 6-8. [CrossRef]

22. Yuan, C.D.; Pu, W.F.; Wang, X.C.; Sun, L.; Zhang, Y.C.; Cheng, S. Effects of Interfacial Tension, Emulsification, and Surfactant Concentration on Oil Recovery in Surfactant Flooding Process for High Temperature and High Salinity Reservoirs. Energy Fuels 2015, 29, 6165-6176. [CrossRef]

23. Aoudia, M.; Al-Maamari, R.S.; Nabipour, M.; Al-Bemani, A.S.; Ayatollahi, S. Laboratory study of alkyl ether sulfonates for improved oil recovery in high-salinity carbonate reservoirs: A case study. Energy Fuels 2010, 24, 3655-3660. [CrossRef]

24. Jia, B.; Tsau, J.; Barati, R. A review of the current progress of $\mathrm{CO}_{2}$ injection EOR and carbon storage in shale oil reservoirs. Fuel 2019, 236, 404-427. [CrossRef]

25. Miller, C.A.; Neogi, P. Interfacial Phenomena (Equilibrium and Dynamic Effects); Taylor \& Francis Group: Abingdon, UK, 2008; ISBN 1420044427.

26. Mo, D.; Jia, B.; Yu, J.; Liu, N.; Lee, R. Study Nanoparticle-Stabilized $\mathrm{CO}_{2}$ Foam for Oil Recovery at Different Pressure, Temperature, and Rock Samples. In Proceedings of the SPE Improved Oil Recovery Symposium, Tulsa, OK, USA, 12-16 April 2014; pp. 1-11.

27. Salager, J.; Marquez, N.; Graciaa, A.; Lachaise, J. Partitioning of Ethoxylated Octylphenol Surfactants in Microemulsion-Oil-Water Systems: Influence of Temperature and Relation between Partitioning Coefficient and Physicochemical Formulation. Langmuir 2000, 5534-5539. [CrossRef]

28. Ren, G.; Zhang, H.; Nguyen, Q. Effect of Surfactant Partitioning on Mobility Control During Carbon-Dioxide Flooding. SPE J. 2013, 18, 752-765. [CrossRef]

29. Tadmouri, R.; Zedde, C.; Routaboul, C.; Micheau, J.C.; Pimienta, V. Partition and water/oil adsorption of some surfactants. J. Phys. Chem. B 2008, 112, 12318-12325. [CrossRef] [PubMed]

30. Acosta, E.; Szekeres, E.; Sabatini, D.A.; Harwell, J.H. Supersolubilization in Surfactant Microemulsions. Langmuir 2003, 38, 186-195. [CrossRef]

31. Rosen, M.J.; Kunjappu, J.T. Surfactants and Interfacial Phenomena, 4th ed.; John Wiley \& Sons: Hoboken, NJ, USA, 2012; ISBN 9780470541944.

32. Boza Troncoso, A.; Acosta, E. The UNIFAC model and the partition of alkyl and alkylphenol ethoxylate surfactants in the excess phases of middle phase microemulsions. Fluid Phase Equilib. 2015, 397, 117-125. [CrossRef]

33. Torrealba, V.A.; Johns, R.T. Partition Coefficient Relations in Surfactant-Oil-Brine Systems for Improved Description of Microemulsion Phase Behavior. In Proceedings of the SPE EOR Conference at Oil and Gas West Asia, Muscat, Oman, 21-23 March 2016. 
34. Kazemzadeh, Y.; Parsaei, R.; Riazi, M. Experimental study of asphaltene precipitation prediction during gas injection to oil reservoirs by interfacial tension measurement. Colloids Surfaces A Physicochem. Eng. Asp. 2015, 466, 138-146. [CrossRef]

35. Viades-Trejo, J.; Gracia-Fadrique, J. Spinning drop method. From Young-Laplace to Vonnegut. Colloids Surfaces A Physicochem. Eng. Asp. 2007, 302, 549-552. [CrossRef]

36. Zhang, D.L.; Liu, S.; Yan, W.; Puerto, M.; Hirasaki, G.J.; Miller, C.A.; Rice, U. Favorable Attributes of Alkali-Surfactant-Polymer Flooding. In Proceedings of the SPE/DOE Symposium on Improved Oil Recovery, Tulsa, OK, USA, 22-26 April 2006.

37. Ravera, F.; Ferrari, M.; Liggieri, L. Adsorption and partitioning of surfactants in liquid-liquid systems. Adv. Colloid Interface Sci. 2000, 88, 129-177. [CrossRef]

38. El-Hamouz, A. Effect of surfactant concentration and operating temperature on the drop size distribution of silicon oil water dispersion. J. Dispers. Sci. Technol. 2007, 28, 797-804. [CrossRef]

39. Fuseni, A.B.; Al-zahrani, B.H.; Alsofi, A.M.; Aramco, S. Critical Micelle Concentration of Different Classes of EOR Surfactants under Representative Field Conditions. In Proceedings of the SPE Kingdom of Saudi Arabia Annual Technical Symposium and Exhibition, Dammam, Saudi Arabia, 24-27 April 2017.

40. Kumar, S.; Mandal, A. Studies on interfacial behavior and wettability change phenomena by ionic and nonionic surfactants in presence of alkalis and salt for enhanced oil recovery. Appl. Surf. Sci. 2016, 372, 42-51. [CrossRef]

41. HUA, X.Y.; ROSEN, M.J. Dynamic Surface Tension of Aqueous Surfactant Solutions: I. basic paremeters. J. Colloid Interface Sci. 1988, 124, 652-659.

42. Kamal, M.S.; Hussein, I.A.; Sultan, A.S. Review on Surfactant Flooding: Phase Behavior, Retention, IFT, and Field Applications. Energy Fuels 2017, 31, 7701-7720. [CrossRef]

43. Gao, B.; Sharma, M.M. A family of alkyl sulfate gemini surfactants. 2. Water-oil interfacial tension reduction. J. Colloid Interface Sci. 2013, 407, 375-381. [CrossRef] [PubMed]

44. Kim, Y.H.; Wasan, D.T. Effect of Demulsifier Partitioning on the Destabilization of Water-in-Oil Emulsions. Ind. Eng. Chem. Res. 1996, 1141-1149. [CrossRef]

(C) 2019 by the authors. Licensee MDPI, Basel, Switzerland. This article is an open access article distributed under the terms and conditions of the Creative Commons Attribution (CC BY) license (http://creativecommons.org/licenses/by/4.0/). 